\title{
Prospective memory: When reminders fail
}

\author{
MELISSA J. GUYNN and MARK A. MCDANIEL \\ University of New Mexico, Albuquerque, New Mexico \\ and \\ GILLES O. EINSTEIN \\ Furman University, Greenville, South Carolina
}

\begin{abstract}
A frequent assumption in the area of prospective memory is that a reminder to do an activity in the future improves the likelihood of doing the activity. The results of four experiments indicated, however, that the most general version of this assumption is incorrect. Subjects were either reminded of a prospective memory task several times during a retention interval or not reminded of the prospective memory task. The most effective reminders referred both to the prospective memory target events and to the intended activity. Reminders that referred only to the target events did not improve prospective memory (relative to a no-reminder control). Reminders that referred only to the intended activity did improve prospective memory, but not to the level of reminders that referred both to the target events and to the intended activity. Instructions to imagine oneself performing the prospective memory task did not further improve prospective memory. Neither the delay between the prospective memory instructions and the prospective memory cover task nor the delay between a reminder and a prospective memory target event significantly influenced performance. The results, which are discussed in terms of theoretical and practical implications, support a new theory of prospective memory and suggest surprising conditions under which reminders fail to benefit prospective memory.
\end{abstract}

When one thinks of remembering, at least two senses of the word come to mind. A person can remember information learned in the past, which is often referred to as retrospective memory. Thus a person can remember the contents of a book, what he or she did last night, or a list of words learned in a memory experiment. A person can also remember to do an activity in the future, which is generally referred to as prospective memory. For instance, a person can remember to give a friend a message, to keep an appointment, or to press a key when a target word appears in a memory experiment. Despite the prevalence of both types of memories in everyday life, only retrospective memory has been extensively studied, and we therefore know comparatively little about prospective memory.

In recent research on prospective memory, the following paradigm has generally been used. Subjects are first given instructions for what they think is the primary task of the experiment. The prospective memory task is embedded within this "cover" activity. This is intended to

This research was supported in part by a National Science Foundation Graduate Research Fellowship to M.J.G., National Institute on Aging (NIA) Grant AGO5627 to M.A.M., and Grant AF 49620-92-J-0437 from the Air Force Office of Scientific Research to Henry L. Roediger III. In addition, preparation of this article was supported in part by NIA Grant AGO8436 to G.O.E. and M.A.M. We are grateful to Betty Glisky for the use of her laboratory facilities at the University of Arizona, and to Scott Newberger, Ellie Corbett, and Barbie Brogan for testing subjects in Experiment 3. Correspondence concerning this article should be addressed to M. J. Guynn at the Department of Psychology, University of New Mexico, Albuquerque, NM 87131 (e-mail: guynn@unm.edu).

-Accepted by previous editor, Geoffrey R. Loftus simulate real-world prospective memory tasks in which people are busily engaged in activities (e.g., working on a manuscript) that they must remember to interrupt at an appropriate point in order to do another intended activity (e.g., give a colleague a message). After the instructions for the cover task, subjects are then given the instructions for the prospective memory task. This often involves asking the subjects to do something (e.g., press a key) whenever they see a particular word in the context of the cover task (Einstein, Holland, McDaniel, \& Guynn, 1992; Einstein \& McDaniel, 1990; McDaniel \& Einstein, 1993). Following the instructions for the prospective memory task, one or more intervening tasks are presented, to discourage continuous maintenance of the prospective memory instruction throughout the experiment. Finally, the cover activity is presented, with no mention of the prospective memory task, and subjects' success at remembering to perform the prospective memory task is assessed.

Initial investigations of prospective memory with this type of paradigm have focused on characteristics of the prospective memory target events that indicate that it is appropriate to perform the intended activity. For example, the familiarity, distinctiveness, and typicality of the target words have been found to affect prospective memory (Brandimonte \& Passolunghi, 1994; Einstein \& McDaniel, 1990; Mäntylä, 1993, 1996; McDaniel \& Einstein, 1993). Other investigations have focused on subject differences (primarily age differences) in prospective memory (Einstein et al., 1992; Einstein \& McDaniel, 1990; Einstein, McDaniel, Richardson, Guynn, \& Cunfer, 1995; Goschke \& Kuhl, 1993, 1996; Maylor, 1990; McDaniel, Glisky, Rubin, Guynn, \& Routhieaux, 1998). 
There has been much less focus on the effect of activities or events occurring during the interval between the prospective memory instructions and the opportunity for performance of the prospective memory task (i.e., during the delay or retention interval). One such factor that would seem to affect prospective memory substantially is the presence of reminders. Although she did not specifically mention reminders, Ellis (1996) proposed that recollections, prompted either by oneself or by another person, might affect prospective memory. According to Ellis, a recollection refers to remembering a delayed intention before the occurrence of a retrieval context during a performance interval. In our terms, the delayed intention is the intended activity, the retrieval context is the appearance of a target event, and the performance interval is the cover task activity. Thus Ellis's view on the function of recollections could be considered to apply to reminders as well. According to her view, such recollections might improve prospective memory by refreshing or strengthening the prospective memory representation (e.g., by increasing its activation level) or by reformulating or altering the prospective memory representation (e.g., by increasing the specificity of the retrieval context).

Mäntylä (1996) proposed that activities directed at planning the prospective memory task might affect prospective memory. According to his view, the planning of activities might improve prospective memory by automatically increasing the activation level of the prospective memory representation, or by creating a more complex or detailed representation that could benefit prospective memory by increasing the number of potential retrieval routes. In our view, it seems that reminders might provide the opportunity either for constructing a plan, or for reviewing or updating an existing plan. This is consistent with Mäntylä's (1996) proposal that one's self-initiated activities while one is doing another task (such as asking oneself what one is supposed to remember) might increase the activation level of the prospective memory representation.

Somewhat surprisingly, the effect of reminders on prospective memory has been tested in few studies, and those studies have produced mixed results. Accordingly, the present study was conducted to determine whether, and under what conditions, reminders benefit prospective memory. We will first highlight the apparently contradictory evidence regarding reminders and prospective memory. We will then present four experiments conducted to address this issue systematically and to provide information about the pertinent theoretical views.

Some experiments have produced evidence consistent with the idea that reminders or recollections benefit prospective memory (Ceci \& Bronfenbrenner, 1985; Einstein \& McDaniel, 1990; Einstein et al., 1995; Harris \& Wilkins, 1982; Kvavilashvili, 1987). Thinking about the prospective memory task during a retention interval, whether by subjective measure (self-reports at the end of an event-based task) or by objective measure (overtly monitoring a clock during a time-based task), ${ }^{1}$ has often been positively correlated with prospective memory. Although the data demonstrate a positive correlation, the interpre- tation is unclear. Increased thinking about the task might lead to better prospective memory, or better prospective memory might lead to increased thinking about the task, or a third factor might be responsible for both. Meacham and Leiman (1982) provided more direct evidence by experimentally manipulating reminders. Providing subjects with a colored tag for their key chains produced a modest increase in promptly returning postcards to the experimenter (relative to not providing such a reminder), but this effect was observed in only some conditions.

Two recent studies urge caution in assuming benefits of reminders to prospective memory. Goschke and Kuhl $(1993,1996)$ investigated prospective memory as a function of whether their subjects were state oriented or action oriented. State-oriented individuals experience more involuntary thought intrusions about future goals than do action-oriented individuals. State-oriented individuals are therefore thought to be more likely to maintain an active representation of a future task in mind, whether or not they expect the future task to be prompted by external cues. Action-oriented individuals are thought to maintain an active representation of a future task in mind only when they do not expect to be prompted by external cues. State-oriented and action-oriented subjects did not differ in prospective memory, leading Goschke and Kuhl to conclude that continuous activation of an intention in explicit memory is not necessary for its execution (when external retrieval cues are available). Because there was no difference in prospective memory between a condition with presumably few or no self-reminders (action-oriented subjects) and a condition with presumably many more selfreminders (state-oriented subjects), the results suggest that reminders do not benefit prospective memory.

In line with this suggestion, Vortac, Edwards, and Manning (1995) found that providing cues continuously during a retention interval (to support rehearsal) did not produce better prospective memory relative to a control condition in which no cues were provided. To the extent that the cues served as reminders, the results suggest that providing reminders during a retention interval does not benefit prospective memory. One potential limitation of the Vortac et al. finding is that subjects might habituate to a continuously present reminder. This is also a concern if Goschke and Kuhl's $(1993,1996)$ state-oriented subjects constantly reminded themselves of their task. Reminders might be most effective if they are presented periodically during a retention interval. In Experiments $1 \mathrm{~A}$ and 1B, we tested this possibility in an attempt to demonstrate a benefit of reminders to prospective memory.

\section{EXPERIMENTS 1A-1B}

The general methodology of these experiments (as well as the subsequent experiments) was similar to that used in most previous laboratory work on prospective memory. Subjects were busily engaged in a cover task, and the prospective memory task was embedded in this cover task. This procedure was adopted because real-world prospective memory tasks often require individuals to inter- 
rupt ongoing activities in order to perform intended (prospective memory) activities. In these experiments, the cover task involved an implicit memory task (word fragment completion in Experiment $1 \mathrm{~A}$ and anagram solution in Experiment $1 \mathrm{~B}$ ), and the prospective memory task involved circling a target word whenever it was produced on the implicit memory task. During the course of the cover task, subjects either received several reminders about the prospective memory task or received no reminders.

\section{Method}

Design and Subjects. The design in both experiments was a one-way between-subjects design, varying whether or not subjects were given prospective memory reminders. Subjects were male United States Air Force recruits in basic training at Lackland Air Force Base in San Antonio, Texas, who participated as part of a basic training requirement. For each experiment, 32 subjects were tested in one group, with 16 subjects receiving three prospective memory reminders and 16 subjects receiving no reminders.

Materials. For the cover task (word fragment completion in Experiment $1 \mathrm{~A}$ and anagram solution in Experiment 1B), 100 words and their corresponding word fragments and anagrams were selected from Appendix C of Roediger, Weldon, Stadler, and Riegler (1992). For half of the subjects in each experiment, anatomy, office, and shadow were the prospective memory target events, and for half of the subjects, anybody, freckle, and bravado were the target events. Twenty other words were selected for an intervening activity that occurred between the prospective memory instructions and the cover task.

Procedure. Some materials and tasks were presented on the computer and some were presented on paper. Each experimental session lasted about $1 \mathrm{~h}$.

The subjects began by learning the three prospective memory target events. Half of the subjects studied anatomy, office, and shadow, and half of the subjects studied anybody, freckle, and bravado. The subjects studied the words for as long as they thought was necessary for learning the words, and they were asked to circle the words if they ever saw them later in the experiment. The subjects then completed several intervening activities.

For the first intervening activity, the subjects were presented with 10 words and with the definitions and initial letters of 10 other words, one at a time on the computer. The subjects were instructed either to read the words, or to read the definitions and initial letters and think of the appropriate words, respectively. The subjects were also asked to rate the pleasantness of each word by typing in a $U$ for unpleasant, an $\mathrm{N}$ for neutral, or a $\mathrm{P}$ for pleasant. They had $10 \mathrm{sec}$ to read or to generate and then to rate each word. They read (or generated) and rated all 10 words in a group before generating (or reading) and rating all 10 words in the other group. Items and the order of the tasks were counterbalanced across subjects. This read/generate task was conducted in order to investigate issues that are not of interest for this paper and thus for the purposes of this paper served merely to occupy the subjects' time. For the second intervening activity, the subjects worked on math problems on paper for $5 \mathrm{~min}$.

Following the two intervening activities in Experiment $1 \mathrm{~A}$, the subjects were given the word fragment completion task, in which the prospective memory task was embedded. We chose an activity that we thought would be engaging for the subjects, and it was presented to them as a word puzzle task. They were asked to write down words (e.g., mascara) that completed the fragments (e.g., $m_{-} s_{-} a \_a$ ). They were presented with 100 word fragments, one at a time for $20 \mathrm{sec}$ each, on the computer. Seventy-seven fragments corresponded to words that subjects had not encountered previously in the experiment, 10 were the words that had been read and 10 were the words that had been generated during the first intervening activity, and 3 were the prospective memory target events. The word fragments corresponding to the prospective memory target events were either the 36th, 60th, and 88th word fragments (anatomy, office, shadow) or the 37 th, 58th, and 89th word fragments (anybody, freckle, bravado). These word fragments were chosen so that each subject would encounter one target event word fragment in each third of the list, excluding the first 10 word fragments, and so that the target event word fragments for the two groups were the same average distance from a reminder. The subjects were given four pages of numbered lines, with 25 lines per page, for this task. After the 25th, 50th, and 75th word fragments (i.e., at the end of each page), the subjects were instructed to put that page into a folder and not look at it again, and to press the space bar to continue with the experiment. After that instruction, the subjects receiving reminders were given the instruction to "Remember the three words that you studied at the beginning of the experiment." The 3 words were not actually presented. Each reminder appeared on the computer for $5 \mathrm{sec}$. The average delay between a reminder and a target event was $3.5 \mathrm{~min}$. The subjects receiving no reminders were not given a 5-sec break. In Experiment 1B, the procedure above was repeated, except that instead of completing word fragments, the subjects solved anagrams (e.g., casmraa) with the first words that came to mind (e.g., mascara).

After the word fragment completion (or anagram solution) task, the subjects were presented with the 10 definitions and first letters of the words that they had generated in the earlier phase of the experiment, and they were asked to write down the words that they had generated. Next, the subjects were presented with the 10 definitions and first letters of the words that they had read in the earlier phase of the experiment, and they were asked to write down the appropriate words. The subjects completed these tasks at their own pace.

Finally, the subjects were asked to recall the prospective memory target events, by writing them down, and then to recognize the target events in a list of other words, by circling them. The distracters for the recognition test were the 97 words that corresponded to the 97 other word fragments/anagrams in the implicit memory task. The subjects completed these tasks at their own pace.

\section{Results}

The results of Experiments $1 \mathrm{~A}$ and $1 \mathrm{~B}$ appear in Table 1. Prospective memory (PM) is expressed as the proportion of completed (word fragment completion) or solved (anagram solution) target events that were circled (circled/completed or circled/solved). The other dependent measures are expressed as the proportion out of three

Table 1

Dependent Measures for Experiment $1 A$ and Experiment 1B as a Function of Number of Reminders

\begin{tabular}{lccccc}
\hline & \multicolumn{2}{c}{ No Reminders } & & \multicolumn{2}{c}{ Three Reminders } \\
\cline { 2 - 3 } \cline { 5 - 6 } \multicolumn{1}{c}{ Measure } & $M$ & $S D$ & & $M$ & $S D$ \\
\hline & Experiment 1A & & & \\
PM targets completed & .73 & .33 & .81 & .24 \\
PM targets circled & .44 & .43 & .48 & .40 \\
Circled/completed (PM) & .59 & .49 & .60 & .45 \\
PM targets recalled & .77 & .36 & .85 & .24 \\
PM targets recognized & .90 & .23 & .85 & .24 \\
& Experiment 1B & & & \\
PM targets solved & .67 & .27 & .63 & .27 \\
PM targets circled & .48 & .36 & .40 & .37 \\
Circled/solved (PM) & .66 & .44 & .57 & .48 \\
PM targets recalled & .77 & .32 & .71 & .32 \\
PM targets recognized & .83 & .30 & .73 & .30 \\
\hline
\end{tabular}

Note $-M$, mean proportion; PM, prospective memory. 
prospective memory target events. The subjects were given credit for prospective remembering if they marked a prospective memory target event in any way. ${ }^{2}$ For this and all subsequent experiments, we report prospective memory collapsed over the three target events because the specific words were confounded with their position in the cover task. All analyses were significant at $p<.05$ unless otherwise indicated.

Experiment 1A. Subjects who received reminders completed no more word fragments (for the target words) than did those who did not receive reminders $(F<1)$. Subjects were as likely to circle the prospective memory targets when they were not given reminders as when they were given reminders, whether or not prospective memory was conditionalized on completing the word fragments (both $F \mathrm{~s}<1$ ). There were .03 prospective memory false alarms (circling a word other than a prospective memory target event during the cover task). There was no difference in retrospective memory for the target events, measured by either recall or recognition (both $F \mathrm{~s}<1$ ). There were .09 recall intrusions (recalling a word other than a prospective memory target event when asked to recall the target words) and .13 recognition false alarms (circling a word other than a prospective memory target event when asked to recognize the target words; this number was high because subjects were encouraged to guess).

Another way to look at the data is to do so in terms of the proportion of subjects in the two groups who had zero, one, two, or three correct prospective memory responses. For the control group, these proportions were .38 (zero), .25 (one), .06 (two), and .31 (three). For the reminder group, these proportions were .31 (zero), .19 (one), .25 (two), and .25 (three). There appears to be no important difference between the two groups in terms of the proportions, paralleling the results of the analysis of variance (ANOVA).

Experiment 1B. Subjects who did not receive reminders solved approximately the same number of anagrams (for the target words) as did those who received reminders $(F<1)$. Subjects were as likely to circle the prospective memory targets when they were not given reminders as when they were given reminders, whether or not prospective memory was conditionalized on solving the anagrams (both $F \mathrm{~s}<1$ ). There were .07 prospective memory false alarms. There was no difference in retrospective memory for the target events, measured by either recall or recognition (both $F \mathrm{~s}<1$ ). There were .09 recall intrusions and .20 recognition false alarms (this number was high because subjects were encouraged to guess) for the prospective memory target events.

If we look at the data in terms of the proportion of subjects in the two groups who had zero, one, two, or three correct prospective memory responses, these proportions were .25 (zero), .25 (one), .31 (two), and .19 (three) for the control group. For the reminder group, these proportions were .38 (zero), .19 (one), .31 (two), and .13 (three). Again there appears to be no important difference between the two groups in terms of the proportions, paralleling the results of the ANOVA.

\section{Discussion}

These results were surprising, in that they consistently indicated no benefit of reminders to prospective memory, even when prospective memory was well below ceiling and could potentially have been improved by reminders. This pattern is contrary both to the intuitively plausible notion that a reminder to do an activity improves the likelihood of doing the activity and to recent theoretical speculation positing several mechanisms by which a reminder might improve prospective memory (Einstein \& McDaniel, 1996; Ellis, 1996; Mäntylä, 1996).

These results are not incompatible with all views, however. Goschke and Kuhl $(1993,1996)$ have suggested that prospective memories have stronger and longer lasting levels of activation than do retrospective memories. It might be that prospective memories exist at a high enough level of activation that any activation stimulated by reminders is redundant and therefore ineffective. A somewhat different analysis (Einstein \& McDaniel, 1996; McDaniel \& Einstein, 1993), the associative link view, is that encoding a prospective memory involves establishing an associative link between the anticipated target event (that indicates the appropriateness of the intended activity) and the intended activity. Prospective remembering then occurs because the associative link is activated past some threshold such that presentation of the target event automatically elicits the representation of the intended activity. In this view, a reminder that focuses only on the target event might not sufficiently activate the critical associative link to improve prospective memory. We tested this idea in Experiment 2.

\section{EXPERIMENT 2}

In this experiment, we manipulated the type of reminder presented to subjects in order to explore the theoretical ideas sketched above. As in our previous experiments, one type of reminder instructed the subjects to think of the target events. A second type of reminder instructed the subjects to think of both the target events and the intended activity. A third type of reminder instructed the subjects to think of both the target events and the intended activity and to imagine themselves performing the prospective memory task in the context of the word puzzle cover task. In addition, the delay between a reminder and a target event was varied, with short delays of about $1 \mathrm{~min}$ or long delays of about $6 \mathrm{~min}$ (relative to the 3.5-min delay in Experiments $1 \mathrm{~A}$ and 1B). We thought it possible that the effect of reminders, if found, could be limited to short delays between a reminder and a target event.

Three predictions can be made about the possible effect of reminders on prospective memory. The associative link view (Einstein \& McDaniel, 1996) implies that the type of reminder is important. The specific implication is that an effective reminder must refer to both the target events and the intended activity. Perhaps referring to the target events is not sufficient to induce subjects to think 
of the intended activity and thereby activate the encoded associative link between the target events and the intended activity. If this view is correct, the reminders that refer to both the target events and the intended activity should improve prospective memory over that in a control condition with no reminders. The reminders that refer to the target events but not the intended activity should not improve prospective memory (as in Experiments 1A and 1B).

A second view that predicts an effect of reminders (e.g., Ellis, 1996; Mäntylä, 1996) suggests that effective reminders might alter the prospective memory trace by making the retrieval context more specific. Accordingly, perhaps only reminders that cause subjects to think about the retrieval context are effective. If this view is correct, the reminders that refer to the retrieval context (i.e., the word puzzle cover task) should improve prospective memory over that in a control condition with no reminders. The reminders that do not refer to the retrieval context should not improve prospective memory. A third view predicts no effect of reminders, in that prospective memories might exist at a high enough level of activation (cf. Goschke \& Kuhl, 1993, 1996) so that no reminders would be effective.

\section{Method}

Design. The design was a $2 \times 3$ between-subjects factorial, varying the delay between a prospective memory reminder and a target event ( $1 \mathrm{~min}, 6 \mathrm{~min}$ ) and the type of prospective memory reminder (target, target + action, target + action + context). In addition, a seventh group of subjects who were not given reminders was included as a control group. The target reminder was the instruction to "Remember the three words that you studied at the beginning of the experiment." The target + action reminder consisted of the target reminder plus the instruction to "Remember what you have to do if you ever see any of those three words." The target + action + context reminder consisted of the target + action reminder plus the instruction to "Imagine yourself actually doing that now in the word puzzle task." The target words were not presented in the reminders. In the short-delay condition, a reminder and target event word fragment were separated by four word fragments, for a delay of about $1 \mathrm{~min}$. In the long-delay condition, a reminder and target event word fragment were separated by 24 word fragments, for a delay of about $6 \mathrm{~min}$.

Subjects. The subjects were 81 University of Arizona students who participated as part of an introductory psychology course requirement. The subjects were tested 1 or 2 at a time in separate rooms. There were either 11 or 12 subjects in each of the seven experimental conditions.

Materials and Procedure. The prospective memory task was embedded in a word fragment completion task. The materials were those used in Experiment 1A. Some materials and tasks were presented on the computer and some were presented on paper. Each experimental session lasted about $45 \mathrm{~min}$.

The subjects began by studying three words (i.e., the prospective memory target events; school, unicorn, celery) for as long as they thought was necessary for learning the words. (The subjects in the different groups did not differ in the time taken for learning the words; see Table 2.) The subjects were asked to circle the words if they ever saw them later in the word puzzle task.

The subjects were then given two tests of retrospective memory in order to introduce a delay between the prospective memory instructions and the opportunity to perform the prospective memory task. First, the subjects studied a 30 -word list, with items presented one at a time for $4 \mathrm{sec}$ each. The subjects were then asked to write down the words for $2 \mathrm{~min}$. Next, the subjects studied a different 30 word list, with items presented one at a time for 2 sec each. The subjects were then asked to circle the words in a list of 60 words, 30 of which had been studied and 30 of which had not, for $2 \mathrm{~min}$.

For the cover task, the subjects were presented with 100 word fragments, 1 at a time, on the computer. Ninety-seven fragments corresponded to words that subjects had not encountered previously in the experiment, and 3 were the prospective memory target events (the 35th, 65th, and 95th word fragments). The words corresponding to those word fragments were chosen to be the prospective memory target events so that the target events would be in the same position for the subjects in both the short- and long-delay conditions and so that no target events would appear in the first 10 word fragments in the task. The subjects were asked to write down the first word that came to mind that completed each fragment. After $10 \mathrm{sec}$, the computer provided a completion for the word fragment, and the subjects were instructed to copy the completion, regardless of whether they had already completed the word fragment. The word fragment and completion appeared on the computer together for $5 \mathrm{sec}$. The subjects were instructed not to go back and work on word fragments encountered earlier. The subjects were given four pages of numbered lines, with two columns of 25 lines per page (one column for completing the fragments and one column for copying the completions) for this task.

Subjects receiving reminders received one reminder before each of the three target events. The target words were not presented in the reminders. The delay between a reminder and target event was varied, with some subjects having a short delay (4 word fragments, or about $1 \mathrm{~min}$ ) and some subjects having a long delay ( 24 word fragments, or about $6 \mathrm{~min}$ ). Each reminder appeared on the computer for $15 \mathrm{sec}$. This duration was longer than in the previous experiments in order for subjects receiving the more detailed reminders, and especially the reminders with the imagery instruction, to have time to follow the instructions. The control subjects, who received no reminders, were not given a 15 -sec break. At the end of the word puzzle cover task, the subjects were asked to recall the three target events that they had studied at the beginning of the experiment.

\section{Results}

Table 2 presents the following dependent measures: study time for the prospective memory target events, the proportion (out of three) of prospective memory target events that were circled (PM), the proportion (out of three) of prospective memory target events that were completed

Table 2

Dependent Measures for Experiment 2 as a Function of Number of Reminders and Type of Reminder

\begin{tabular}{|c|c|c|c|c|c|c|c|c|}
\hline \multirow[b]{3}{*}{ Measure } & & & \multicolumn{6}{|c|}{ Three Reminders } \\
\hline & \multicolumn{2}{|c|}{$\begin{array}{c}\text { No } \\
\text { Reminders } \\
\text { Control }\end{array}$} & \multicolumn{2}{|c|}{ Target } & \multicolumn{2}{|c|}{$\begin{array}{l}\text { Target } \\
\text { Action }\end{array}$} & \multicolumn{2}{|c|}{$\begin{array}{c}\text { Target } \\
\text { Action } \\
\text { Context }\end{array}$} \\
\hline & $M$ & $S D$ & $M$ & $S D$ & $M$ & $S D$ & $M$ & $S D$ \\
\hline Study time* (sec) & 16 & 7 & 15 & 7 & 17 & 8 & 17 & 6 \\
\hline PMt & .42 & .41 & .28 & .43 & .95 & .16 & .76 & .35 \\
\hline PM targets completed & .50 & .22 & .74 & .25 & .88 & .22 & .76 & .25 \\
\hline PM targets recalled & .86 & .22 & .84 & .28 & .94 & .17 & .90 & .25 \\
\hline RM recall & .30 & .08 & .32 & .10 & .33 & .12 & .34 & .14 \\
\hline RM recognition & .79 & .22 & .79 & .15 & .75 & .20 & .74 & .17 \\
\hline
\end{tabular}

Note-PM, prospective memory; RM, retrospective memory. *Time spent studying the prospective memory target words during the initial instructions. † Because target completions were provided to subjects, the proportion is the number of prospective memory responses divided by the total number of prospective memory trials (i.e., 3 ). 
(on the word fragment completion cover task), the proportion (out of three) of prospective memory target events that were recalled (at the end of the experiment), and the proportion (out of 30) of words recalled and recognized on the retrospective memory (RM) tests during the delay interval. All analyses significant at $p<.05$ unless otherwise indicated. For all dependent variables, the initial analysis was a 2 (delay of reminder) $\times 3$ (type of reminder) between-subjects ANOVA in which the control group was excluded. These analyses did not reveal any main effects of delay or any interactions involving delay (largest $F=$ 2.07). Thus the no-reminder control group was included in subsequent one-way ANOVAs of the effect of type of reminder collapsed across the variable of delay of reminder.

Prospective memory. Subjects were given credit for prospective memory responses when they marked the prospective memory target events in any way. ${ }^{3}$ Prospective memory is expressed as a proportion out of three prospective memory target events (collapsed over completed and uncompleted word fragments because a completion was provided for each word fragment).

The one-way ANOVA indicated a significant effect of the type of reminder on prospective memory $[F(3,77)=$ $17.19, M S_{\mathrm{e}}=.12$ ]. (There were .004 prospective memory false alarms.) Pairwise comparisons indicated that in comparison with the results for the control group, target reminders did not improve prospective memory $[F(1,77)$ $=1.31]$, but target + action reminders improved prospective memory $[F(1,77)=18.73]$; and target + action + context reminders improved prospective memory $[F(1,77)$ $=8.04]$ but tended to produce worse prospective memory than did target + action reminders $[F(1,77)=3.48]$ $(p<.07)$.

The proportion of subjects in the different conditions who had zero, one, two, or three correct prospective memory responses are as follows: (1) for the control condition, .42 (zero), .08 (one), .33 (two), and . 17 (three); (2) for the target reminder condition, .70 (zero), .00 (one), .09 (two), and .22 (three); (3) for the target + action reminder condition, .00 (zero), .05 (one), .05 (two), and .91 (three); and (4) for the target + action + context reminder condition, .13 (zero), .04 (one), .25 (two), and .58 (three). The proportions appear consistent with the ANOVAs, in that most subjects receiving either no reminders or target reminders had none correct, whereas most subjects receiving either type of target + action reminder had three correct.

Retrospective memory. The one-way ANOVA indicated a significant effect of the type of reminder on completing the word fragments with the prospective memory target events $\left[F(3,77)=6.65, M S_{\mathrm{e}}=.06\right]$. More target event word fragments were completed by subjects receiving reminders than by subjects in the control condition. There were significant differences between the control group and all three groups receiving reminders $[F(1,77)=$ 8.02 (target), $F(1,77)=19.82$ (target + action), and $F(1,77)=9.91($ target + action + context $)]$. The difference between target and target + action + context reminders was not significant $(F<1)$, and the difference between target + action and target + action + context reminders was not significant $[F(1,77)=2.70, p<.11]$, but the difference between target and target + action reminders was marginally significant $[F(1,77)=3.90, p<.06]$.

The one-way ANOVA indicated no significant effect of the type of reminder on recall of the prospective memory target events $(F<1)$. (There were .05 recall intrusions.) Subjects in the different groups did not differ on the two measures of retrospective memory that were given during the interval between the prospective memory instructions and the word fragment completion task (both $F \mathrm{~s}<1$ ).

\section{Discussion}

The results are inconsistent with the view that a prospective memory is sufficiently activated so that reminders do not produce further activation and hence do not produce benefits to prospective memory. The present experiment clearly demonstrated that some types of reminders do produce benefits. It also reinforced the results of Experiments $1 \mathrm{~A}$ and $1 \mathrm{~B}$ in that the instruction to remember the target events per se did not improve prospective memory. These data are consistent with the view (Einstein \& McDaniel, 1996; McDaniel, 1995) that what is important to prospective memory is the activation of an encoded associative link between the target events and the intended activity, and that reminders that activate the associative link should produce benefits to prospective memory. The results are consistent with this view, in that the instruction to remember the target events and the intended activity did improve prospective memory, whereas the instruction to remember just the target events did not improve prospective memory.

It is unclear why prospective memory in the target + action + context condition did not improve prospective memory over that in the target + action condition. Perhaps subjects did not try or were not able to imagine the retrieval context. Alternatively, perhaps subjects imagined the retrieval context at the expense of thinking about the target events and the intended activity. A third possibility is that subjects in all groups imagined the retrieval context, whether or not they had been instructed to do so. A final possibility is that our particular context manipulation was simply not useful in improving prospective memory. Regardless, because both target + action reminders and target + action + context reminders produced better prospective memory than did target reminders and the control group, it appears that what is necessary for effective prospective memory reminding is reinstatement of the association between the prospective memory target events and the intended activity. It is possible, however, that the target + action reminders and the target + action + context reminders were effective not because they reinstated the association but because they reinstated the intended activity. We addressed this possibility in Experiment 3.

The failure to find an effect of the target reminders in Experiments $1 \mathrm{~A}, 1 \mathrm{~B}$, and 2 could also be explained by a 
familiarity and search view of prospective memory (Einstein \& McDaniel, 1996; cf. Mandler, 1980). According to this view, the familiarity of the target event prompts a directed search for the significance of the target event. This directed search could lead a person to recover the target event's significance - namely, that it is the signal to perform an intended activity. In this view, instantiation of the target events as reminders should produce increments in familiarity, such that when a target event actually occurs, the perceived familiarity is sufficiently high to induce a search for the target event's significance. It is possible that in Experiments 1A, 1B, and 2, the target reminders did not increment the familiarity of the prospective memory target events. According to Mandler's (1980) theory of recognition memory, familiarity is based on integration of an item's perceptual features. In Experiments 1A, $1 \mathrm{~B}$, and 2 , the target events were not actually presented in the reminders, so there was little or no opportunity for integration of the perceptual features of the target events. The recognition data of Experiments $1 \mathrm{~A}$ and $1 \mathrm{~B}$ support this explanation, because subjects who did receive and who did not receive reminders did not differ in their recognition of the prospective memory target events. According to this view, target reminders should be effective only if they include presentation of the target events, thus allowing integration of the perceptual features of the target events. Alternatively, the view that emphasizes the importance of the associative link between the target events and the intended activity (Einstein \& McDaniel, 1996; McDaniel, 1995) predicts that these reminders would not improve prospective memory because the reminders do not focus on the associative link. To test these predictions, we included the target events in the target reminders in Experiment 3.

Before we turn to Experiment 3, it is worth noting that reminders produced different effects on word fragment completion and on prospective memory in Experiment 2. The instruction to remember the target events was sufficient to increase subjects' likelihood of completing the word fragments with the target events, but it was not sufficient to increase subjects' likelihood of circling the prospective memory target events. Therefore, indirect retrospective memory processes might not be involved in prospective remembering, contrary to preliminary correlational results suggesting otherwise (McDaniel \& Einstein, 1993; see also McDaniel, Robinson-Riegler, \& Einstein, 1998).

\section{EXPERIMENT 3}

To explore the ideas sketched above, we manipulated the type of reminder presented to subjects. As in the previous experiments, target reminders instructed the subjects to think of the target events (and the target words were presented). A combined target + action reminder instructed the subjects to think of both the target events and the intended activity (and both the target words and the desired action $[\mathrm{F} 10]^{4}$ were presented). We also in- cluded a new type of reminder: Action reminders instructed the subjects to think of the intended activity (and the desired action [F10] was presented). If the effect of target + action reminders in Experiment 2 was due simply to reminding subjects of the intended activity, the action reminders should be as effective as the target + action reminders in Experiment 3.

Finally, because it remained possible that target reminders alone could be effective at longer retention intervals (i.e., the interval between the prospective memory instruction and the prospective memory target event), we varied the delay between the prospective memory instruction and the cover task (in which the prospective memory task was embedded). Some conditions had a short delay of about $4 \mathrm{~min}$ and other conditions had longer delays of about $20 \mathrm{~min}$. The delay between a reminder and a prospective memory target event was always $1 \mathrm{~min}$ (the short-delay condition of Experiment 2).

\section{Method}

Design. The design was a $2 \times 4$ between-subjects factorial, varying the delay between the prospective memory instructions and the cover task ( $4 \mathrm{~min}, 20 \mathrm{~min}$ ) and the type of prospective memory reminder (no-reminder control, target, action, target + action). The target reminder was the instruction to "Remember the three words that you studied at the beginning of the experiment." The action reminder was the instruction to "Remember the key that you have to press later in the experiment." The target + action reminder was the combined instruction to "Remember the three words that you studied at the beginning of the experiment and remember the key that you have to press later in the experiment if you ever see one of the three words." The target words and/or the desired action (F10) were presented in the reminders. The subjects in two control groups (short delay, long delay) did not receive reminders. In the short-delay condition, the prospective memory instructions and the cover task were separated by a recall test, for a delay of about $4 \mathrm{~min}$. In the longdelay condition, the prospective memory instructions and the cover task were separated by a recall test, a recognition test, and two questionnaires, for a delay of about $20 \mathrm{~min}$.

Subjects. The subjects were 66 University of New Mexico students tested individually and 32 Furman University students tested in small groups of 4 . The subjects participated as part of an introductory psychology course requirement. There were either 12 or 13 subjects in each of the eight experimental conditions, with 4 Furman students and either 8 or 9 New Mexico students assigned to each condition.

Materials and Procedure. The prospective memory task was embedded in a word fragment completion task. The materials were those used in Experiments $1 \mathrm{~A}$ and 2. Some materials and tasks were presented on the computer, and some were presented on paper. Experimental sessions lasted about $45 \mathrm{~min}$ in the short-delay conditions and $1 \mathrm{~h}$ in the long-delay conditions.

The subjects began by studying three words (i.e., the prospective memory target events; school, unicorn, celery) for as long as they thought was necessary for learning the words. (The subjects in the different groups did not differ in the time taken to learn the words; see Table 3.) The subjects were asked to press the F10 key if they ever saw the words as completions in the word puzzle task.

The subjects were then given either one (short-delay conditions) or four (long-delay conditions) activities, to introduce a delay between the prospective memory instructions and the opportunity to perform the prospective memory task. First, all subjects studied a 30 -word list, with items presented one at a time for $4 \mathrm{sec}$ each. The subjects were then asked to write down the words for $2 \mathrm{~min}$. Next, 
the subjects in the long-delay conditions studied a different 30 -word list, with items presented one at a time for $2 \mathrm{sec}$ each. The subjects were then asked to circle the words in a list of 60 words, 30 of which had been studied and 30 of which had not, for $2 \mathrm{~min}$. Next, the subjects in the long-delay conditions answered two questionnaires: the 90-item SCL-90R (Symptom checklist; Derogotis, 1977) and the 36-item Action Control Scale (Kuhl, 1994).

The cover task was identical to that in Experiment 2. Subjects receiving reminders received one reminder before each of the three target events. In contrast to Experiment 2, the target words and/or the desired action were presented in the reminders. Specifically, the target words were presented in the target reminders, F10 was presented in the action reminders, and both the target words and F10 were presented in the target + action reminders. The control subjects, who received no reminders, were given a $15-\mathrm{sec}$ break from the cover task at the same time that the other subjects received reminders. During the breaks, the control subjects counted backwards by threes from a three-digit number.

At the end of the word puzzle cover task, the subjects were asked to recall the three words that they had studied at the beginning of the experiment and to recall the key that they were supposed to press if they ever saw one of the three words. The subjects were also asked if they had followed the instructions when the reminders were presented and remembered what the reminders had instructed them to remember.

\section{Results}

Table 3 presents the following dependent measures: study time for the prospective memory target events, the proportion (out of three) of prospective memory target events to which subjects pressed the F10 key (PM), the proportion (out of three) of prospective memory target events that were completed (on the word fragment completion cover task), the proportion (out of three) of prospective memory target events that were recalled (at the end of the experiment), the proportion (out of one) of times that the F10 response was recalled (at the end of the experiment), and the proportion (out of 30 ) of words recalled (short-delay conditions) and recognized (shortand long-delay conditions) on the retrospective memory $(\mathrm{RM})$ tests during the delay interval. All analyses were significant at $p<.05$ unless otherwise indicated.

Table 3

Dependent Measures for Experiment 3 as a Function of Number of Reminders and Type of Reminder

\begin{tabular}{|c|c|c|c|c|c|c|c|c|}
\hline \multirow[b]{3}{*}{ Measure } & & & \multicolumn{6}{|c|}{ Three Reminders } \\
\hline & \multicolumn{2}{|c|}{$\begin{array}{c}\text { No Reminders } \\
\text { Control } \\
\end{array}$} & \multicolumn{2}{|c|}{ Target } & \multicolumn{2}{|c|}{ Action } & \multicolumn{2}{|c|}{$\begin{array}{l}\text { Target } \\
\text { Action }\end{array}$} \\
\hline & $M$ & $\overline{S D}$ & $M$ & $S D$ & $M$ & $S D$ & $M$ & $\overline{S D}$ \\
\hline Study time* $(\mathrm{sec})$ & 15 & 8 & 14 & 8 & 12 & 7 & 12 & 4 \\
\hline $\mathrm{PM} \dagger$ & .31 & .35 & .36 & .47 & .56 & .38 & .82 & .22 \\
\hline PM targets completed & .58 & .25 & .89 & .16 & .67 & .25 & .82 & .22 \\
\hline PM targets recalled & .89 & .19 & 1.00 & 0 & .81 & .31 & .99 & .07 \\
\hline PM action recalled & .92 & .28 & .80 & .41 & .96 & .20 & .96 & .20 \\
\hline & .31 & .13 & .28 & .10 & .31 & .12 & .30 & .10 \\
\hline RM recognition & .76 & .17 & .57 & .18 & .76 & .23 & .62 & .22 \\
\hline
\end{tabular}

Note-PM, prospective memory; RM, retrospective memory. *Time spent studying the prospective memory target words during the initial instructions. Because target completions were provided to subjects, the proportion is the number of prospective memory responses divided by the total number of prospective memory trials (i.e., 3 ).
Prospective memory. Prospective memory is expressed as a proportion out of three prospective memory target events (collapsed over completed and uncompleted word fragments). ${ }^{5}$ The data were submitted to a 2 (length of delay) $\times 2$ (target reminder present/absent) $\times 2$ (action reminder present/absent) between-subjects ANOVA. (A target reminder was present in the target and in the target + action conditions and was absent in the control and in the action conditions, and an action reminder was present in the action and in the target + action conditions and was absent in the control and in the target conditions.)

This analysis did not reveal any main effects of delay or any interactions involving delay (largest $F=1.43$ ). There were significant main effects of target reminder presence and action reminder presence $[F(1,90)=4.25$, $M S_{\mathrm{e}}=.14$ and $F(1,90)=22.61$, respectively], but the interaction was not significant $[F(1,90)=1.91]$. Planned pairwise comparisons were conducted to test the theoretical predictions outlined earlier. These comparisons indicated that target reminders did not improve prospective memory over the control condition $(F<1)$ but that action reminders and target + action reminders significantly improved prospective memory $[F(1,90)=5.70$ and $F(1,90)$ $=22.79$, respectively]. Importantly, the target + action reminders were significantly more effective than the action reminders $[F(1,90)=5.93]$.

The proportion of subjects in the different conditions who had zero, one, two, or three correct prospective memory responses are as follows: (1) for the control condition, .54 (zero), .04 (one), .38 (two), and .04 (three); (2) for the target reminder condition, .60 (zero), .04 (one), .04 (two), and .32 (three); (3) for the action reminder condition, .20 (zero), .24 (one), .24 (two), and .32 (three); and (4) for the target + action reminder condition, .00 (zero), .08 (one), .38 (two), and .54 (three). The proportions appear consistent with the ANOVAs, in that most subjects receiving either no reminders or target reminders had none correct, whereas most subjects receiving target + action reminders had three correct. Interestingly, subjects receiving action reminders were quite evenly distributed in terms of the number of correct prospective memory responses, perhaps indicating a mixture of strategies in response to the presentation of the reminders (e.g., some subjects treating the action reminders like action-alone reminders, and other subjects treating the action reminders like target + action reminders)

Retrospective memory. Three-factor $(2 \times 2 \times 2)$ between-subjects ANOVAs paralleling those conducted for prospective memory were computed for fragment completion and recall of the prospective memory information. There was a significant benefit of a target reminder on completion of the word fragments with the target words $\left[F(1,90)=26.75, M S_{\mathrm{e}}=.05\right]$. There were no other significant effects. There was also a significant benefit of a target reminder on recall of the prospective memory target events $\left[F(1,90)=14.20, M S_{\mathrm{e}}=.03\right]$, and no other 
significant effects. Finally, there was a marginally significant benefit of an action reminder on recall of the intended activity (pressing the $F 10$ key) $\left[F(1,90)=2.85, M S_{\mathrm{e}}=\right.$ $.08, p<.10]$. There were no other significant effects.

There was no significant effect of the reminders on retrospective memory as measured by the recall test given during the delay interval (largest $F<1$ ). The subjects in the long delay groups were also given a recognition test. The groups did differ in retrospective memory as measured by the recognition test, in that there was a significant effect of a target reminder $\left[F(1,45)=8.30, M S_{\mathrm{e}}=\right.$ $.04]$. This result was surprising, because the type of reminder was a prospective memory manipulation, and ostensibly subjects in the different reminder conditions received identical treatments through the end of the recognition test. Neither the main effect of an action reminder nor the interaction was significant (both $F \mathrm{~s}<1$ ).

\section{Discussion}

These results replicate the results of Experiments 1A, $1 \mathrm{~B}$, and 2 , in that the instruction to remember the target events did not improve prospective memory, but the combined instruction to remember the target events and the intended activity did improve prospective memory. The results are extended in that the instruction to remember the intended activity did improve prospective memory, but not to the level of the target + action reminders. This result gives further weight to the conclusion that what appears necessary for the most effective prospective memory reminding is reinstatement of the association between the prospective memory target events and the intended activity.

The results of the questionnaire are informative on this point. Of the 25 subjects receiving the action reminders, only 5 said that they followed the instruction and thought of the intended activity but not the target words while the reminder was present. Twenty said that they thought of both the intended activity and the target words. Prospective memory averaged .14 for the subjects who said that they followed the instruction but 67 for the subjects who said that they did not follow the instruction (and thought of both the intended activity and the target words). These results call into some question the benefit of action-only reminders, because it appears that the action reminders might have functioned like target + action reminders for $80 \%$ of the subjects.

The results also indicate an interesting dissociation between several different measures of memory. Specifically, the reminders produced different effects on recall of the target events and completion of the word fragments with the target events, on the one hand, and on recall of the intended activity, on the other. The reminders produced yet a different effect on prospective memory. Presenting reminders about the target events (target or target + action) was sufficient to improve performance on the tasks relying on memory for the target words: recalling the target words and completing the word fragments with the target words. Similarly, presenting reminders about the intended action (action or target + action) was sufficient to improve performance (at least marginally) on the task relying on memory for the intended activity: recalling the intended activity. In contrast to these results, our planned pairwise comparisons indicated that the target reminders alone did not improve prospective memory. The action reminders alone did improve prospective memory, but there is perhaps some doubt whether or not some subjects spontaneously extended the action reminders into target + action reminders. The more important point is that the target + action reminders improved prospective memory beyond the level of the action reminders alone. So it appears that what is necessary for the most effective prospective memory reminding is a reminder about both the target events and the intended activity.

A possible alternative interpretation of the effects of reminders on prospective memory is that the reminders simply produced better retrospective memory for the target events and/or for the intended activity. The dissociations just discussed counter this interpretation. Specifically, the differences in recall of the target events and the intended activity do not parallel the differences in prospective memory. For instance, subjects receiving target reminders had better recall of the target events than did subjects receiving action reminders ( $1.00 \mathrm{vs} .81)$, yet their prospective memory was worse (.36 vs. .56 ). Similarly, subjects receiving target + action reminders had better prospective memory than did subjects receiving action reminders (.82 vs. .56), yet their recall of the intended activity was the same (.96).

The results are also incompatible with the familiarity and search view of prospective memory (Einstein \& McDaniel, 1996). We expected that presentation of the target events would increment the integration of their perceptual features and thereby increase their familiarity. Evidence that familiarity was incremented by the reminders comes from the finding that subjects receiving target reminders had better free recall and better word fragment completion of the prospective memory target events than did subjects not receiving reminders. Unfortunately, an error in data collection prevented us from collecting the measure of recognition of the prospective memory target events that would be the most informative on this issue. It appears, however, that increases in familiarity (at least increases in familiarity produced and measured by the present procedures) do not mediate prospective memory, since prospective memory did not differ for subjects receiving target reminders and subjects not receiving reminders.

The results are generally consistent, however, with a view that suggests conditions under which reminders might not benefit prospective memory. According to this view (Einstein \& McDaniel, 1996), which emphasizes the activation of an encoded associative link between the target events and the intended activity, some, but not all, reminders should benefit prospective memory. Specifically, reminders that focus on the associative link between the target events and the intended activity should improve prospective memory, whereas reminders that do not en- 
courage processing of the associative link should not improve prospective memory.

\section{GENERAL DISCUSSION}

The results of four experiments investigating the effect of reminders on prospective memory demonstrate that reminders that referred only to the target events did not improve prospective memory over that in a control condition with no reminders (Experiments 1A, 1B, 2, and 3 ). Reminders that referred only to the intended action did improve prospective memory over that in a control condition (Experiment 3). Reminders that referred to both the target events and the intended activity also did improve prospective memory over that in a control condition, as well as over that in target-only and actiononly reminder conditions (Experiments 2 and 3). The additional instruction for subjects to imagine themselves performing the prospective memory task in the context of the word puzzle cover task did not further benefit prospective memory (Experiment 2). Two other variables also failed to produce an effect on prospective memory: the delay between a reminder and a target event ( $1 \mathrm{~min}$ vs. $6 \mathrm{~min}$; Experiment 2 ) and the delay between the prospective memory instructions and the prospective memory cover task (4 min vs. $20 \mathrm{~min}$; Experiment 3 ).

\section{Theoretical Implications}

The results are compatible with general theories of prospective memory that might be referred to as "activation" views. According to these views, prospective memory representations exist at a certain level of activation, and recollections or reminders increase the level of activation further (Einstein \& McDaniel, 1996; Ellis, 1996; Mäntylä, 1996). Moreover, in these views, reminders increase the likelihood that the activation levels of the prospective memory representations (including the encoded associative link) will be sufficient to support prospective remembering at the time that the target events are encountered.

A critical factor emphasized in one of the activation accounts is the association between the target events and the intended activity (Einstein \& McDaniel, 1996; McDaniel, 1995). According to this view, activation of this association is essential for prospective remembering, and one implication is that reminders must activate this association in order to be effective. Support for this view comes from the present finding that the most effective reminders referred to both the target events and the intended activity of the prospective memory task. Reminders that referred only to the target events did not improve prospective memory over that in a control condition with no reminders. Reminders that referred only to the intended activity did improve prospective memory over that in a control condition, but our questionnaire data indicate that this might have been due to the fact that the action reminders functioned like target + action reminders for $80 \%$ of the subjects. Regardless, reminders that referred only to the intended activity did not improve prospective memory to the level of reminders that referred to both the target events and the intended activity.

Our ideas may also provide information about Vortac et al.'s (1995) finding that presentation of a cue to facilitate rehearsal of a prospective memory task during a retention interval did not produce better prospective memory than did a condition without a cue. Their rehearsal cues appear to have specified the intended activity but not the target events and thus support our conclusion that presenting action reminders alone might not benefit prospective memory (if subjects do not think of the target events). If the cues had included the critical associative link between the target events and the intended activity, the rehearsal (reminder) cues might have been effective.

Our results are also consistent with a neuropsychological model of prospective memory (McDaniel, 1996; McDaniel, Robinson-Riegler, \& Einstein, 1998) that is based in part on Moscovitch's (1994) neuropsychological account of associative memory. According to Moscovitch's account, the hippocampal system accomplishes associative memory tasks by first encoding an association between a target and a response. When the target is presented at test, if there is sufficient interaction, or ecphory (Semon, 1904, cited in Tulving, 1983) between the target and the memory trace, the hippocampal system automatically evokes the association between the target and the response so that the response can be given. If there is not sufficient ecphory, the hippocampal system does not evoke the association. The relation to prospective memory is apparent. An association is formed between a prospective memory target event and an intended action (in much the same way that an association is formed between a target and a response in a retrospective associative memory task). At test, the target event is presented as a cue to perform the intended action. The hippocampal or associative memory system is thought to evoke automatically the association between the target event and the intended action so that the intended action can be remembered and performed. According to the model, presentation of a target + action reminder benefits prospective memory by reinforcing the encoded association so that the probability of its being evoked in the presence of the target event is increased.

One other result is consistent with the conclusion that to be effective, reminders must activate the target and the action. In Experiment 2, supplementing the effective target + action reminder with the instruction to imagine oneself actually performing the prospective memory task in the appropriate context did not further improve prospective memory. This finding underscores the primary importance of the association between the target event and the intended activity in prospective memory.

The results are inconsistent with the idea that recollections or reminders might benefit prospective memory by increasing the specificity of the retrieval context (see Ellis, 1996) or by producing a more elaborated representation to increase the number of potential retrieval cues (cf. Mäntylä, 1996). We attempted to facilitate these possible functions of reminders by instructing subjects to imagine 
themselves performing the prospective memory task in the context of the word puzzle cover task. We thought that this activity would create a representation more specifically tied to the retrieval context and/or provide more retrieval cues (e.g., due to motor encoding; Engelkamp, Zimmer, Mohr, \& Sellen, 1994; see also Koriat, Ben-Zur, \& Nussbaum, 1990). Although Koriat et al. have provided evidence that encoding conditions that foster internal visualization of a task improve retrospective memory, there was no evidence that reminding subjects of the retrieval context and imaging the motor actions benefited prospective memory (above that achieved by a reminder that focused on just the target events and the intended activity). Of course, perhaps our instructions were not effective in increasing the specificity of the retrieval context. Or perhaps subjects imagined the retrieval context at the expense of thinking about the target events and the intended activity. Or perhaps all subjects spontaneously imagined the retrieval context. The latter possibility is not consistent, however, with the finding that subjects receiving target reminders apparently did not go beyond the information that was presented in the reminders (Experiments 1A, 1B, 2, and 3). Further work with different methods to increase the specificity of the encoding of the retrieval context during reminders is needed in order to provide converging tests of this possible function of reminders.

\section{Reminders in Other Prospective Memory Tasks}

An experiment by Burkes (1994) suggests possible conditions under which target-only reminders might produce some benefits. Subjects verified sentences and tried to remember to press the return key on the computer keyboard if they ever saw a prospective memory target word in a sentence. Presenting the target word briefly (for $17 \mathrm{msec}$ ) two sentences prior to the sentence containing the clearly visible prospective memory target word (to which the subjects had been instructed to respond) improved prospective memory in comparison with control conditions in which either a neutral cue ("XXXX") or no cue was presented. To the extent that this $17-\mathrm{msec}$ presentation of the target word served as a reminder, the results suggest that presenting target reminders can benefit prospective memory under certain conditions.

There are a number of differences between Burkes's (1994) experiment and our experiments that might be responsible for the different effects. His cover task (sentence verification) demanded semantic or conceptual processing, whereas many researchers believe that our cover tasks (word fragment completion and anagram solution) demanded orthographic or perceptual processing. In addition, Burkes's experiment involved presenting a single target word (not an explicit reminder) for a very short time (for $17 \mathrm{msec}$ ), whereas our experiments involved reminding subjects about the target words (and in one experiment the target words were actually presented) for a relatively long time (for either 5 or $15 \mathrm{sec}$ ). Any of these factors, or others, such as the delay between the prime or the reminder and the target event, could be responsible for the different effects. We note them here mainly to point out that further work will be necessary in order to illuminate the reasons for the differences in findings.

The present experiments all involved event-based prospective memory tasks, in which subjects responded to the occurrence of a target event (e.g., a target word). It has been suggested that time-based prospective memory tasks, in which subjects respond at a particular target time or after a particular amount of time has elapsed, are more challenging than event-based prospective memory tasks, because subjects must monitor the passage of time, and not just monitor for the occurrence of an event (Einstein et al., 1995). One untested possibility is that target-only reminders (e.g., presenting the target time as a reminder) might produce some benefits on more difficult timebased prospective memory tasks, even though they did not produce benefits on our event-based prospective memory task.

\section{Practical Implications}

Several possible caveats about the practical implications of our results are (1) that our results were obtained via laboratory experiments, not real-world settings, (2) that our stimuli and our task might be considered artificial in comparison with more real-world stimuli and tasks, and (3) that our prospective memory tasks and our target-action associations might be considered arbitrary or nonmeaningful in comparison with more real-world tasks and associations (but in our minds, no mere so than tying a string around a finger to remind oneself of something). With these caveats in mind, we note some implications for the practical issue of what types of reminders are effective in real-world prospective remembering. The results suggest that an effective reminder must specify both the target events and the intended activity of the prospective memory task. To the extent that specification of the target events evokes remembering of the intended activity, specification of the intended activity might not be necessary. Likewise, to the extent that specification of the intended activity evokes remembering of the target events, specification of the target events might not be necessary. However, often it cannot be guaranteed that remembering the target events will evoke remembering of the intended activity and that remembering the intended activity will evoke remembering of the target events. For this reason, the most effective reminders are those that specify both the target events and the intended activity. For example, a person might intend to give a friend a message when he or she sees the person at work. Our data imply that periodically rehearsing the name of the friend, or the fact that one has to give a message, throughout the day, are not the best ways to remind oneself of the prospective memory task. Instead, a better way is to rehearse both the name of the friend and the fact that one also has to give the friend a message. The results of Experiment 2 suggest that further specification of the context for the prospective memory task is unnecessary. That is, it might not be necessary to remind oneself to give the message to the friend specifically during the day at work. Effective rehearsal or reminding appears to be that which increases 
the likelihood that the appearance of a target event automatically evokes remembering of the intended activity, and that appears to be rehearsal or reminding that focuses on both the target event and the intended activity.

\section{REFERENCES}

Brandimonte, M. A., \& Passolunghi, M. C. (1994). The effect of cue-familiarity, cue-distinctiveness, and retention interval on prospective remembering. Quarterly Journal of Experimental Psychology, 47A, 565-587.

BURKES, M. (1994, July). The effect of local context on prospective memory performance in a semantic processing task. Paper presented at the Practical Aspects of Memory Conference, College Park, MD.

Ceci, S. J., \& Bronfenbrenner, U. (1985). "Don't forget to take the cupcakes out of the oven": Prospective memory, strategic timemonitoring, and context. Child Development, 56, 152-164.

Derogotis, L. R. (1977). SCL-90R: Administration, scoring, and procedures manual-I. Baltimore: Johns Hopkins.

Einstein, G. O., Holland, L. J., MCDaniel, M. A., \& Guynn, M. J. (1992). Age related deficits in prospective memory: The influence of task complexity. Psychology \& Aging, 7, 471-478.

Einstein, G. O., \& MCDANIEL, M. A. (1990). Normal aging and prospective memory. Journal of Experimental Psychology: Learning, Memory, \& Cognition, 16, 717-726.

EINSTEIN, G. O., \& MCDANIEL, M. A. (1996). Retrieval processes in prospective memory: Theoretical approaches and some new empirical findings. In M. A. Brandimonte, G. O. Einstein, \& M. A. McDaniel (Eds.), Prospective memory: Theory and applications (pp. 115-141). Hillsdale, NJ: Erlbaum.

Einstein, G. O., McDaniel, M. A., Richardson, S. L., Guynn, M. J., \& CUNFER, A. R. (1995). Aging and prospective memory: Examining the influences of self-initiated retrieval processes. Journal of Experimental Psychology: Learning, Memory, \& Cognition, 21, 996-1007.

ElLIs, J. A. (1996). Prospective memory or the realization of delayed in tentions: A conceptual framework for research. In M. A. Brandimonte, G. O. Einstein, \& M. A. McDaniel (Eds.), Prospective memory: Theory and applications (pp. 1-22). Hillsdale, NJ: Erlbaum.

EngelKamp, J., Zimmer, H. D., Mohr, G., \& Sellen, O. (1994). Memory of self-performed tasks: Self-performing during recognition. Memory \& Cognition, 22, 34-39.

GoschKE, T., \& KUHL, J. (1993). Representation of intentions: Persisting activation in memory. Journal of Experimental Psychology: Learning, Memory, \& Cognition, 19, 1211-1226.

GoschKe, T., \& KuhL, J. (1996). Remembering what to do: Explicit and implicit memory for intentions. In M. A. Brandimonte, G. O. Einstein, \& M. A. McDaniel (Eds.), Prospective memory: Theory and applications (pp. 53-91). Hillsdale, NJ; Erlbaum.

HarRis, J. E., \& WiLkINS, A. J. (1982). Remembering to do things: A theoretical framework and an illustrative experiment. Human Learning, 1, 123-136.

Koriat, A., Ben-Zur, H., \& Nussbaum, A. (1990). Encoding information for future action: Memory for to-be-performed tasks versus memory for to-be-recalled tasks. Memory \& Cognition, 18, 568-578.

KuHL, J. (1994). Action versus state orientation: Psychometric properties of the action-control scale (ACS-90). In J. Kuhl \& J. Beckmann (Eds.), Volition and personality: Action versus state orientation (pp. 47-59). Toronto: Hogrefe.

KVAVILASHYILI, L. (1987). Remembering intention as a distinct form of memory. British Journal of Psychology, 78, 507-518.

MANDLER, G. (1980). Recognizing: The judgment of previous occurrence. Psychological Review, 87, 252-271.

MäNTYLÄ, T. (1993). Priming effects in prospective memory. Memory, 1, 203-218.

MÄNTYLÄ, T. (1996). Activating actions and interrupting intentions Mechanisms of retrieval sensitization in prospective memory. In M. A Brandimonte, G. O. Einstein, \& M. A. McDaniel (Eds.), Prospective memory: Theory and applications (pp. 93-113). Hillsdale, NJ: Erlbaum.

MAYLOR, E. A. (1990). Age and prospective memory. Quarterly Journal of Experimental Psychology, 42A, 471-493.

MCDANIEL, M. A. (1995). Prospective memory: Progress and processes.
In D. L. Medin (Ed.), The psychology of learning and motivation (Vol. 33, pp. 191-221). San Diego: Academic Press.

McDaniel, M. A. (1996, April). Prospective memory: No longer forgotten. Paper presented at the 66th annual meeting of the Rocky Mountain Psychological Association, Park City, UT.

McDaniel, M. A., \& Einstein, G. O. (1993). The importance of cue familiarity and cue distinctiveness in prospective memory. Memory, $1,23-41$.

McDaniel, M. A., Gursky, E. L., Rubin, S. R., Guynn, M. J., \& RouTHIEAUX, B. C. (1998). Prospective memory: A neuropsychological siudy. Manuscript submitted for publication.

MCDaniel, M. A., Robinson-Riegler, B., \& Einstein, G. O. (1998). Prospective remembering: Perceptually driven or conceptually driven processes? Memory \& Cognition, 26, 121-134.

Meacham, J, A., \& Leiman, B. (1982). Remembering to perform future actions. In U. Neisser (Ed.), Memory observed: Remembering in natural contexts (pp. 327-336). San Francisco: W. H. Freeman.

Moscovitch, M. (1994). Memory and working with memory: Evaluation of a component process model and comparisons with other models. In D. L. Schacter \& E. Tulving (Eds.), Memory systems 1994 (pp. 269-310). Cambridge, MA: MIT Press.

RoEdiger, H. L., III, WELdon, M. S., STAdLER, M. L., \& RIEGLeR, G. L. (1992). Direct comparison of two implicit memory tests: Word fragment and word stem completion. Journal of Experimental Psychology: Learning, Memory, \& Cognition, 18, 1251-1269.

SEMon, R. (1904). Die Mneme als erhaltendes Prinzip im Wechsel des organischen Geschehens. Leipzig: William Engelmann.

TulviNG, E. (1983). Elements of episodic memory. New York: Oxford University Press.

VorTac, O. U., Edwards, M. B., \& Manning, C. A. (1995). Functions of external cues in prospective memory. Memory, 3, 201-219.

\section{NOTES}

1. In an event-based prospective memory task, subjects are asked to do something whenever a particular target event (e.g., the word rake) occurs in the cover task. In a time-based prospective memory task, subjects are asked to do something at a particular time (e.g., at 3:00 p.m.) or after a particular amount of time has elapsed (e.g., after $5 \mathrm{~min}$ ) in the cover task.

2. For Experiment 1A, there was no difference between a lenient and a strict scoring criterion. For Experiment $1 \mathrm{~B}, 3$ subjects responded correctly using a lenient criterion but incorrectly using a strict criterion. This resulted in prospective memory scores of $M=.44$ (not conditionalized on anagram solution) and $M=.59$ (conditionalized on anagram solution) in the no-reminder control group (with $S D=.38$ and $S D=$ .46 , respectively) and prospective memory scores of $M=.31$ (not conditionalized) and $M=.45$ (conditionalized) in the reminder group (with $S D=.35$ and $S D=.48$, respectively). Consistent with the analysis using the lenient criterion, using a strict criterion, there was not a significant difference between the groups on either measure of prospective memory (both $F \mathrm{~s}<1$ ).

3. For Experiment 2,14 subjects responded correctly using a lenient criterion but incorrectly using a strict criterion. This resulted in prospective memory scores of $M=.33(S D=.43)$ in the control condition, $M=.20(S D=.40)$ in the target reminder condition, $M=.77(S D=$ $.40)$ in the target + action reminder condition, and $M=.53(S D=.45)$ in the target + action + context reminder condition. Consistent with the analysis using a lenient criterion, using a strict criterion, there was a significant effect of the type of reminder on prospective memory $\left[F(3,77)=7.49, M S_{\mathrm{e}}=.18\right]$.

4. We changed the intended activity from circling the target words to pressing the F10 key when a target word appeared, so that the reminders that referred to the desired action did not have to refer to the target words.

5. For Experiment 3, the computer only recorded the prospective memory response if subjects pressed the F10 key. No other alternative response was recorded, which means that the prospective memory data reflect a strict response criterion.

(Manuscript received June 11, 1996; revision accepted for publication January $21,1997$. 